\title{
Assessing Users Satisfaction and Experience on Academic Websites: A Case of Selected Nigerian Universities Websites
}

\author{
Arnold A. OJUGO \\ Department of Mathematics/Computer Science, Federal University of Petroleum Resources Effurun, Nigeria \\ E-mail: ojugo.arnold@fupre.edu.ng, arnoldojugo@yahoo.com, arnoldojugo@gmail.com \\ Andrew O. EBOKA \\ Department of Computer Science Education, Federal College of Education (Technical) Asaba, PMB 1044, Nigeria. \\ E-mail: an_drey2k@yahoo.com
}

Received: 22 June 2018; Accepted: 09 August 2018; Published: 08 October 2018

\begin{abstract}
Webometric seeks to assess the convenience as well as experience of users, as they interact with webbased system. Businesses use websites as means to present their deliverables to a larger audience. The aim of which is to change, refocus and reshape a user's image of an organization. Today, it has been extended to facilitate activities such as recruitment etc. We investigate usability of selected Nigerian Universities based on expert review guideline with a focus on the Federal University of Petroleum Resources Effurun (FUPRE), compare the scores achieved in each criterion among selected university websites. Result shows common strengths, common weakness, unique strengths and unique weakness of these university websites. Some websites were found to have unique characteristics which separated them from the other ones. Most university websites successfully ensured that the trust and credibility section as well as their homepages received the highest scores in their usability analysis. Some of the sites on the contrary, struggled to ensure good search usability and form, and data entry criteria, as many of the websites did not even include the mentioned essential functions in their web design. Findings suggest that even the top ranked universities have websites which is lacking in some different website usability areas.
\end{abstract}

Index Terms-Webometrics, footprint, universities, websites ranking, web navigation, credibility, FUPRE, academic website.

\section{INTRODUCTION}

The Internet continues to advance the field of informatics by housing web-based contents as researchers continue to seek effective means to acquire knowledge and desired data. As users sought to satisfy their evergrowing data appetite as a product delivered across platforms, knowledge czars and engineers continues to proffer better techniques, medium and processes to deliver these to their clients [24]. Thus, it has become imperative for web designers to build products aimed at satisfying users' quest, experience and interaction. Institutions today, employ rich web-based contents as means for high visibility, which will ultimately aid them to capitalize on profits and benefit by promoting their products in a competitive market. A good website can change, recreate and refocus a user's image of an organization [10-11]. Designing such website is quite a daunting task that is rippled with many challenging feats such as navigation, contents, openness etc - all of which guides the users as they peruse a site's pages, to keep users' interest engaged and lead to satisfied users' experience, and knowledge as outcome its byproduct cum outcome [33-34].

A major reason for the growing scientific interest over the Internet is in the already high and ever-growing amount of web-users, web server, applications and contents. Despite the variety of search engines available, Google has remained a predominant search technology whose success overtime, can be attributed to Google's capability to offer largest index, innovative new services, highly optimized performance and usability for webbased contents [14-17]. The study about navigation carried out in various dimensions as the field of web usage mining ensures a navigation pattern as users visits a website and its data are easily recorded in the web log file $[4-5,35]$.

\section{A. Related Works}

[25] focused on need of metrics and emphasized that metrics help organizations generate more effective and successful websites. [8] Survey on Korean organizations found that a key enabler of website success measurement is website metrics. These metrics play two important roles: They determine if a website performs to the expectations of the users and the business running the site, and they identify website design problems.

An earlier attempt to measure the Web was introduced in 1996 by Bray, who tried to answer questions such as 
the size of the Web, its connectivity, and the visibility of sites [5]. [30] Introduced a new metric assessing the success of information-driven websites that merged user behavior, site content, and structure while utilizing user feedback. [4] studied published Web metrics from 1992 to 2004 using 3-dimensional Web quality model (WQM). They classified 385 Web-metrics. The WQM defines a cube structure in which three aspects are considered when testing a website: Web features, lifecycle processes, and quality aspects. The results confirm that most metrics ( $48 \%$ of the metrics studied) are usability metrics, and $44 \%$ of them related to "presentation". In this respect, usability is a quality attribute that assesses how easy user interfaces are to use and also refers to methods for improving ease-of-use during the design process [20]. In the life cycle dimension, the majority of metrics are related to operation $(43.2 \%)$ and maintenance processes $(30 \%)$. In addition, a large number of metrics are automated $(67 \%)$.

\section{B. Universities Web Usability In Nigeria}

[27] investigated the views of 178-users from 5-design criteria: navigation, download speed, personalization, ease of use, and accessibility of commerce sites. The objective was to find which criteria is most relevant to success in web design and if gender plays a role. Results determined that, navigation and ease of use were the most important criteria; whereas, personalization and customization were least important. Female participants gave more emphasis on of these web usability criteria than males. [37] focused on the relative significance of site design in six distinctive areas: financial, e-commerce, education, medical, entertainment and government. Some feats were important for all sites; while, some sites were only ranked high for particular type of sites. Educational and medical websites prefer the comprehensiveness of information but other websites do not.

Using Microsoft Usability Guidelines, [1] investigated the usability of web sites focusing on 2 kinds of user, customers and investors. They researched on four sectors: online bookstores, automobile manufacturers, airlines and car rental agencies. The result stated that content is the most important and then ease of use. [31] discussed influence of 6 web-design issues (data content, navigation ease, download speed, personalization, security, availability and accessibility) where 2 -users evaluated 200-websites. They took 40 sites from each of the following categories, portals and search engines, retail, entertainment, news and information, and financial services. Results showed that security and customization did not play a role in website's usability but the rest of them did.

[36] used a 2-factor model design and evaluation on CNN's website: hygiene factors that makes a site useable and to avoid user dissatisfaction, and motivator factors to enhance user satisfaction but its absence may not cause dissatisfaction. Study revealed that hygiene factors will include: technical, navigation, privacy and security systems; While, motivator factors include: enjoyment, credibility and cognitive outcome of the websites. Thus, of all participants eighty six percent believed that website type affects the way they judge this.

\section{Study Objectives}

1. Evaluate and compare individual website result and ranking based on the Usability Expert Review guidelines with specific focus on the Federal University of Petroleum Resources Effurun (FUPRE)

2. Finding the common strengths and weaknesses and also identifying the unique ones.

Section I is introduction - giving a background of literatures on which the study spins off from and a view of the study objectives. Section II relates to materials and methods used by the study. Section III displays results and discusses the findings thereof. Section IV discusses the common design feats of interest such as the common strengths, common weaknesses, unique strengths and unique weaknesses in the design of the selected websites. Lastly, Section V is summary and conclusion.

\section{MATERIALS AND METHODS}

\section{A. Research Instruments}

Criteria for evaluating the usability of educational websites were constructed from guidelines on Usability Expert Review: www.userfocus.co.uk/resources/guidelines.html, which scores a website based on 9-criteria. It has 20-heuristics to evaluate the usability of home pages, 44-heuristics on how well a web site supports a user' s tasks, 29heuristics on navigation and information architecture, 23heuristics on forms and data entry, 13-heuristics on trust and credibility, 23-heuristics on writing and content quality, 38-heuristics on page layout and visual design, 20-heuristics on search and 37-heuristics on help support, feedback and error tolerance. A total of 247 guidelines is scored to evaluate a website's usability.

\section{B. Selected Websites}

It is seen through http://www.webometrics.info, an international university ranking website, to select the top 7-universities in Nigeria to conduct the review. The selected universities are:

1. University of Ibadan [www.ui.edu.ng]

2. Covenant University Ota [covenantuniversity.edu.ng]

3. Obafemi Awolowo University Ife [www.oauife.edu.ng]

4. University of Lagos Akoka [www.unilag.edu.ng]

5. University of Nigeria Nsukka [www.unn.edu.ng]

6. University of Port-Harcourt Choba [www.uniport.edu.ng]

7. University of Agriculture Abeokuta [www.unaab.edu.ng] 
8. Federal University of Petroleum Resources Effurun [www.fupre.edu.ng] - as the case study in focus.

\section{Procedure, Analytics and Evaluation Criteria}

The process of this review will go through the guideline. Mark each site with a positive or negative score. For each checklist, if guideline does not comply with the site - we rate $a-1$; If it complies, we rate $a+1$; If we cannot decide if it complies, we rate a 0 . Guidelines are context specific, and not all of them are applicable to review a university website. Some guidelines were kept blank. The results are shown in graph to allow for easy comparison, the various feats of interest such as strengths and weaknesses are therein. This, in turn will enable us know what feats to focus on so as to enhance a user's experience. We also analyze factors the sites struggles to address. The criteria include: (1) Homepage, (2) Task orientation, (3) Navigation, (4) Forms/Data Entry, (5) Trust/credibility, (6) Writing and content quality, (7) Page layout and visual design, (8) Search usability, and (9) Help and error tolerance.

\section{RESULT, DISCUSSION AND FINDINGS}

\section{A. Overall Usability}

1. University of Ibadan shows overall rating of above $84 \%$ with above $72 \%$ in 3-criteria: homepage, writing and content quality, trust/credibility. Search usability of her website has got the poorest score.

2. Covenant University Ota shows website has overall rating of above $82 \%$ with above $70 \%$ also in: home page, writing and content quality, trust and credibility. Search usability had the poorest score.

3. Obafemi Awolowo University Ife shows an overall ranking of above $84 \%$ with above $74 \%$ in 3-criteria: home page, writing and content quality, trust and credibility. Search usability had the poorest score.

4. Obafemi Awolowo University Ife shows an overall ranking of above $84 \%$ with above $74 \%$ in 3-criteria: home page, writing and content quality, trust and credibility. Search usability also, had poorest score.

5. University of Lagos Akoka show overall rating of above $72 \%$ with above $70 \%$ in 3-criteria: home page, writing and content quality, trust and credibility. Search usability also, had the poorest score.

6. University of Nigeria Nsukka shows an overall rating of above $70 \%$ with above $69 \%$ in 3-criteria: home page, writing and content quality, trust and credibility. Search usability also, had poorest score.

7. University of Port-Harcourt Choba: The results show that the website has an overall rating of above $84 \%$. It also has above $68 \%$ in 3 -criteria: home page, writing and content quality, trust and credibility. Search usability had the poorest score.

8. University of Agriculture Abeokuta: The results show that the website has an overall rating of above $84 \%$. It also has above $56 \%$ in 3 -criteria: home page, writing and content quality, trust and credibility. Search usability also, had the poorest score.

9. Federal University of Petroleum Resources Effurun as the case study in focus show an overall rating of $20 \%$. It also has above $52 \%$ in 3 -criteria: home page, writing and content quality, trust and credibility. Search usability has the poorest score.

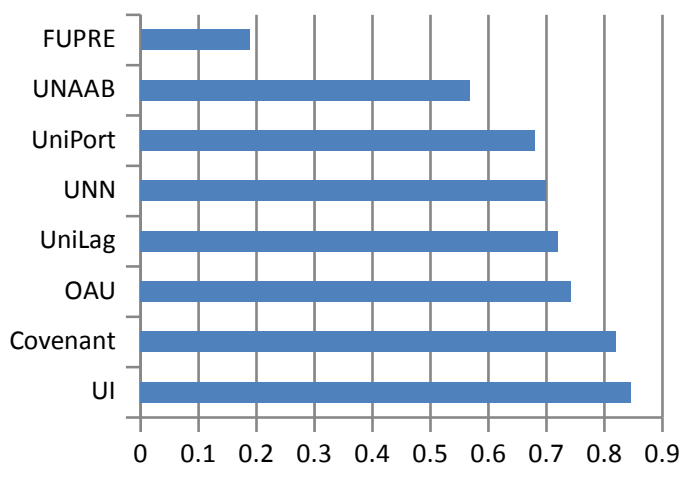

Fig.1. Overall Relative ratings of all Selected Websites

Table 1. Overall Relative Score of all Universities websites' usability

\begin{tabular}{cccc}
\hline $\begin{array}{c}\text { World } \\
\text { Ranking }\end{array}$ & $\begin{array}{c}\text { Nigeria } \\
\text { Ranking }\end{array}$ & $\begin{array}{c}\text { University Name } \\
\text { (Abbreviated) }\end{array}$ & $\begin{array}{c}\text { Relative } \\
\text { Score }(\mathbf{0}-\mathbf{1})\end{array}$ \\
\hline $\mathbf{1 3 3 5}$ & 1 & UI & 0.87615 \\
$\mathbf{1 7 8 8}$ & 2 & Covenant & 0.86322 \\
$\mathbf{1 9 8 6}$ & 3 & OAU & 0.82891 \\
$\mathbf{2 6 1 3}$ & 4 & UniLag & 0.80720 \\
$\mathbf{2 6 5 2}$ & 5 & UNN & 0.79818 \\
$\mathbf{2 8 4 0}$ & 6 & UniPort & 0.77332 \\
$\mathbf{2 9 1 4}$ & 7 & UNAAB & 0.76201 \\
$\mathbf{1 2 0 1 5}$ & 62 & FUPRE & 0.284901 \\
\hline
\end{tabular}

\section{B. Result Based on Criteria}

1. Home-Page Usability: Here, about 5-participants used, UI website obtained highest score among the university websites; while, FUPRE had lowest score.

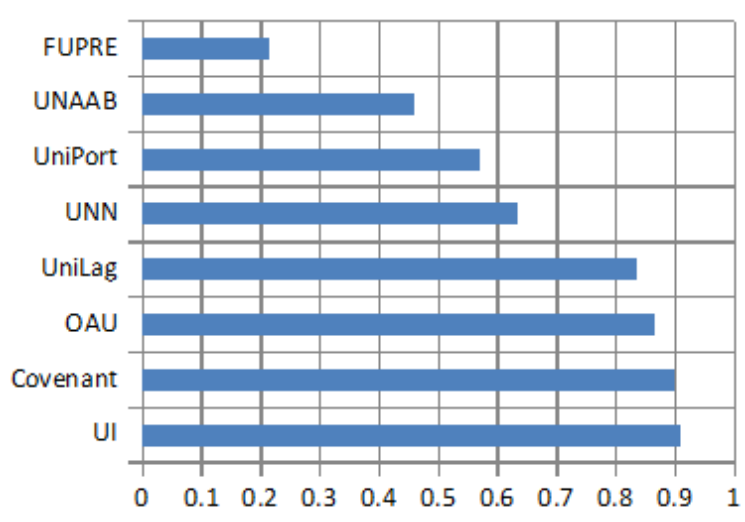

Fig.2. Graph of Selected website Homepage 
2. Task Orientation: Both UI and Uniport obtained the highest score; while, UniLag had the lowest score.

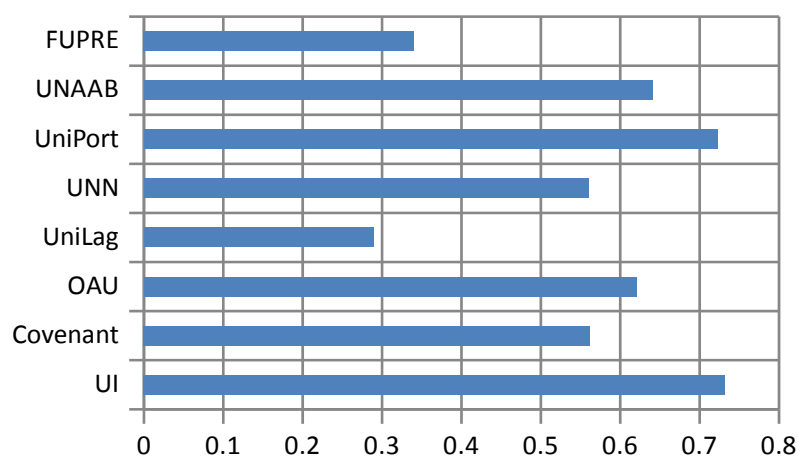

Fig.3. Graph of selected Websites on Task Orientation

3. Navigation: Covenant and Unilag obtained highest score; while, FUPRE had lowest score.

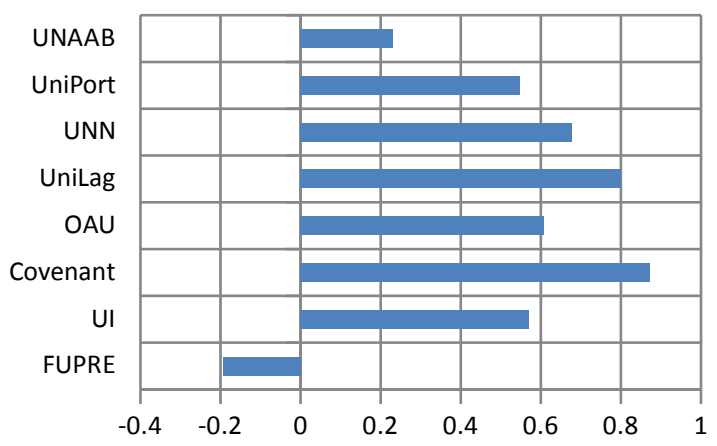

Fig.4. Graph of selected Websites on Navigation criteria

4. Form/Data Entry: UniPort, Covenant and UI obtained the highest score; while, UNN had lowest score.

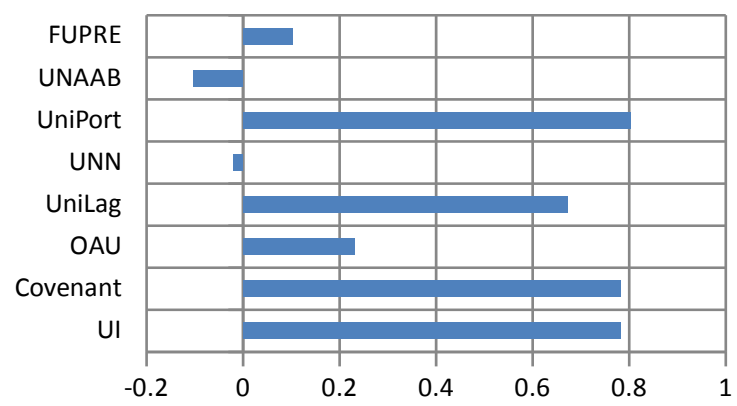

Fig.5. Graph describing rating of selected Academic Websites on Form and Data Entry criteria

5. Trust/Credibility: Covenant, UI, OAU and Unilag obtained highest score; while, UNN and UniPort had the lowest score.

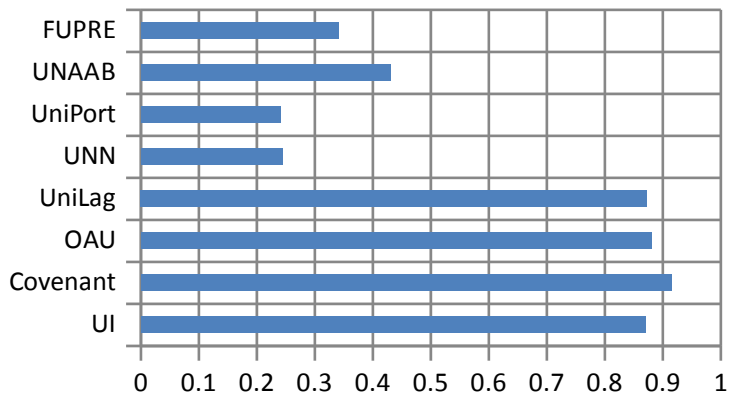

Fig.6. Graph describing rating of selected Academic Websites on trust and Credibility criteria

6. Writing and Content Quality: UI, UNN and OAU had the highest score; while, UNAAB had the lowest score.

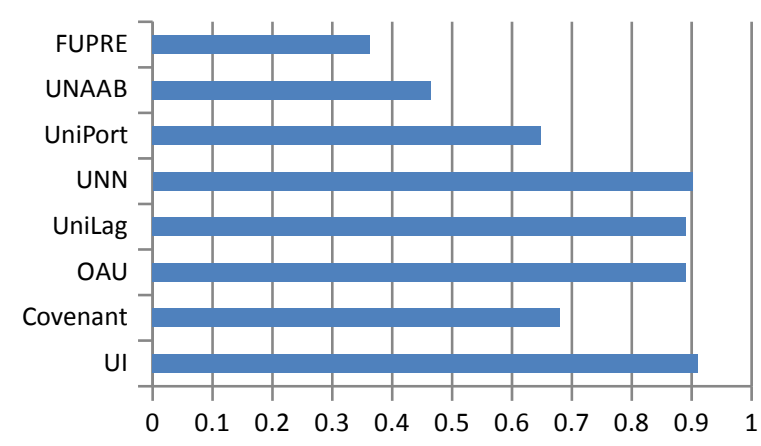

Fig.7. Graph describing rating of selected Academic Websites on Writing and Content Quality criteria

7. Page Layout and Visual Design: UI, Covenant and OAU obtained highest score; while, UNAAB and FUPRE had the lowest score.

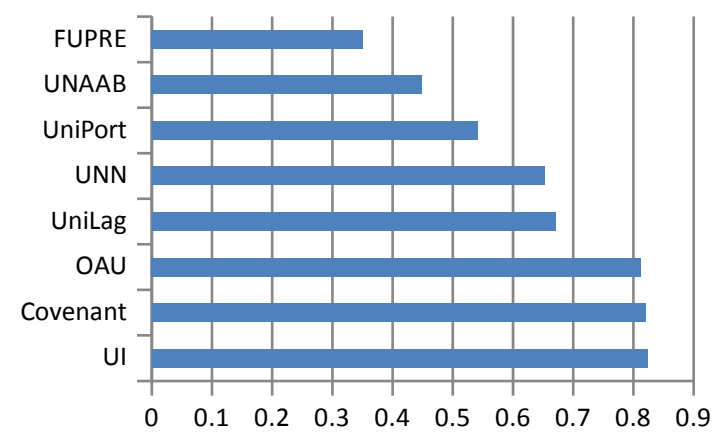

Fig.8. Graph describing rating of selected Academic Websites on Page Layout and Visual Design criteria

8. Search Usability: UI obtained the highest score; while, FUPRE had the lowest score in the negative. 


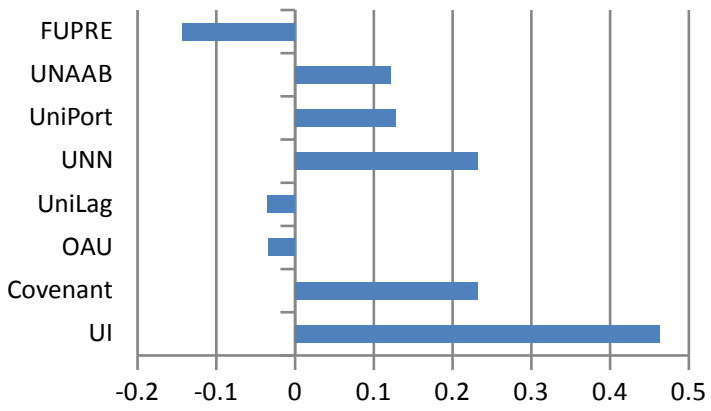

Fig.9. Graph describing rating of selected Academic Websites on Search Usability criteria

9. Help, Feedback and Error: UI obtained the highest score; while, UniPort had the lowest score.

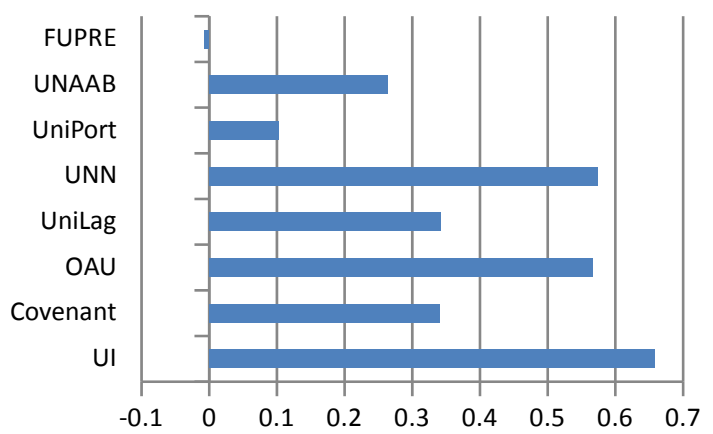

Fig.10. Graph describing rating of selected Academic Websites on Help and Feedback criteria

\section{COMMON AND UNIQUE UNIVERSITY DESIGN ISSUES}

\section{A. Common Strengths}

1. Homepage usability has 20 guidelines. These guidelines were maintained by most of the universities. All selected university websites have useful content presented on their homepage, or within one click of homepage. Also, all eight (8) universities websites have links on the homepage begin with the most important keyword. All the websites show: title of homepage which provide good visibility in search engines; And, the homepage of the websites has a memorable URL. Other guidelines such as, the homepage does not look like other pages in the site. By looking at the home page, a first time user will understand where to start etc. All these were followed by most of the university websites.

2. Task orientation: All the selected websites avoided unnecessary registration. Also, university websites that have online admission form follows the guideline of not making the users enter the same information more than once. The use of metaphors is easily understood by users in all the sites. All websites data formats follow an appropriate cultural conventions - though, the details of the software's internal workings are not exposed to user in all of the websites.

3. Navigation: Information that users most likely needs to ease navigation from one page to another in most sites. Usually the same navigation bar is used in all pages. In 6 of these websites, one finds major sections available from every page as the navigation menu stays the same and takes you to your desired information.

4. Forms and data entry: Only 7-universities provided the online admission form for users. Among them 6 of the websites have field labels that clearly explain what entries are desired. All of the forms are validated before they are submitted except for 1 .

5. Trust and credibility: All of the websites' content is up-to-date, authoritative and trustworthy. None of the sites give advertisements, especially popups in their site. Most of the sites made sure each page is clearly branded so that the user knows he is still in same site.

6. Writing and content quality: All the websites consists of compelling and unique contents. E.g. Information about UNN can and will be only found in their website. All of the websites have received a positive mark for organizing information hierarchically, from a general to the specific content as well as organized in a clear and logical way. All buttons and link labels start with action words for all the university websites.

7. Page layout and visual design: All except 2 of the sites can be used without scrolling horizontally. 15 out of these 21 websites have used fonts that are readable in other cases like University of Ibadan used blue, black and red fonts on white background in most of the pages. FUPRE in some cases, used gray fonts and background on white background making it hard to read. None of the graphics used in these websites will be confused with banner ads.

8. Search usability: All the websites provided search options and have a search results page (though 2 of them shows duplicate results). 6 of these websites have received a positive score for having the searching option that covers the entire web site and not just a portion.

9. Help, feedback and error tolerance: For using any of these websites a user does not need to consult user manuals or other external information. For all the websites with an online application form, the confirmation pages are clear. There is sufficient space between targets to prevent users from hitting multiple or incorrect targets in all of the websites.

\section{B. Common Weaknesses}

1. Homepage usability: Some websites had common mistakes such as: 5-of-the-8 university websites do not have items on the home page that are focused on users' key tasks.

2. Task orientation: 2-of-the-8 selected university sites fail to make the critical path to information 
on units such as the admission, department, college information clear. None of the websites took full advantage of the activities allocated to the user, like: actions that can be done automatically by the site (e.g. postcode lookup). All of the university websites fail to give option for course comparisons when this was necessary for the task. All of the websites have failed to provide varying levels of explanation in help and error messages.

3. Navigation and IA: Most of the websites, does not have a simple structure with a clear conceptual model as well as no unnecessary levels. 1 of the sites did not use consistent design and color throughout its website pages. For example, FUPRE's website uses different color for most of the department's individual pages. Moreover, links do not look the same in the different sections of the site in 5 of these websites.

4. Forms/Data entry: Every website with an admission form has made the mistake of not utilizing the opportunity of automatically entering field formatted data. Users need to enter characters like $£$ or \%. For example: Birth Date needs to be entered in the format: $\mathrm{dd} / \mathrm{mm} / \mathrm{yyyy}$. The field is not formatted on its own if you input a value like this: ddmmyyyy. None of the university websites pre-warn the users, where external data or information is needed for completion of the forms.

5. Trust and credibility: Most of the websites do not contain any data regarding third-party support to verify accuracy of their information. For example, none of the university mentioned any organization to verify their credibility.

6. Writing and content quality: None of the websites follow the guideline of beginning contents with the conclusion or implication and writing text in an inverted pyramid style. Also, all the websites use passive voice for writing their content. All of the websites failed to get a positive score for defining acronyms and abbreviations when used for the first time.

7. Page layout and visual design: Two of these websites failed to ensure appropriate screen density for the target users and their tasks. For example: FUPRE website has a lot of information is clustered together in the homepage. 4 of these sites failed to have a consistent, clearly recognizable look and feel that will engage users.

8. Search usability: All 8 universities websites with search option, none of the sites shows a user what was searched for in search results page and it is also not that easy to edit and resubmit the search. All of these websites show the mistake of not offering ideas or options for improving the query if no results are returned. None of the websites have a search engine that provides an option for similarity search or automatic spell checking system that looks for plurals and synonyms.

9. Help, feedback and error tolerance: All of these websites could not provide easy to get help service in the right form and at the right time. 3 out of 8 websites does not provide immediate and good feedback when needed. None of the websites show the users how to do common tasks with demonstrations. 4 websites failed to ensure that data is not lost by providing saving options in their online admission form pages.

\section{Unique Strengths}

1. Homepage usability: Though, some universities websites failed to address these guidelines cum issues, some others were successful in considering these factors. For example: only 3-of-theuniversities stated their value proposition in the home page with a tagline or welcome blurb, like: UI, Covenant and UNN shows a tagline in the sliding picture of the home page.

2. Task orientation: Only 2 university sites successfully kept their sites requiring of user, a minimal scroll and click activity. Moreover, only 2 university websites use graphs to describe numerical values rather than data charts. Display of work flow is not shown in any websites except for one. Only 2 university websites have included the privacy policy in their website.

3. Navigation: Navigation should be broad and shallow with many items on a menu; But, most websites did not follow this rule. The sitemap providing an overview of the site's content is not available in any of the university website. Navigation-only pages (such as the home page) can be viewed without scrolling from, in none of these websites.

4. Forms/Data entry: Fields on forms contain hints, examples or model answers to demonstrate the expected input in only one private university websites. Moreover, only one university website got positive score regarding the fact that, pulldown menus, radio buttons and check boxes are preferred more than text fields on the forms.

5. Trust and credibility: It could not be traced or found in any of the university websites, an expert (credentials) acknowledgment on the sites; Though, all 8-websites did provide online contact options for users that need or require assistance.

6. Writing and content quality: 6 university websites have been found to prefer using bulleted and numbered lists in preference to narrative text. Also, 6 websites got positive score for using headings and sub-headings and short paragraphs to make pages are quick to scan.

7. Page layout and visual design: Only 6 university websites followed the guideline of confirming that items that are not clickable do not have characteristics that suggest that they are. None of the university website made their pages formatted for printing, or had print icon that suggests its print friendly. 3 websites had colors that do not work well together as mentioned earlier - like FUPRE's 
homepage.

8. Search usability: Only 3 university websites managed to get a positive score for providing search results that are clear, useful and ranked by relevance. 2-of-the- 8 websites have search results pages that clearly show how many results were retrieved, and the number of results per page can be configured by the user.

9. Help, feedback and error tolerance: 4 university website has received a positive point for having FAQ or on-line help which provides step-by-step instructions to help users. None of the university had a customized 404 pages, which includes tips on how to find the missing page and links to "Home".

\section{Unique Weaknesses}

1. Homepage usability: Some university websites failed to adopt the guidelines which were followed by most others. 3 websites failed to address the issue of grouping all corporate information in one distinct area. For example, with UniLag, UniPort and UNAAB - the membership of and Partner's Activism should be in "About Us" section and not on the home page. Another weakness found between these websites is that the navigation choices are not ordered in the most logical or taskoriented manner. Some university websites also have 2 navigation bars, one at the beginning and the other one on the left which seems unnecessary and confusing for users.

2. Task orientation: 4 university sites had some irrelevant, unnecessary and distracting information in their websites. Users do not need to remember information from place to place in most websites except for two.

3. Navigation and IA: 3 university websites failed to use labels to categorize and accurately describe information in that category.

4. Forms and Data entry: 2 university sites did not clearly distinguish between "required" and "optional" fields on the online admission forms. In one of the websites, the required fields are not marked at first but if you submit without filling them up then those fields will show * beside them.

5. Trust and credibility: 3-of-the-8 university websites have typographic errors and spelling mistakes. Like in UniLag, its original links redirects users to their new website. Also website admission requirement in the navigation bar is wrongly spelt.

6. Writing/Content quality: 4 university sites failed to use content specifically created for the website, some did not clearly label their pages with a descriptive and useful title that makes sense as a bookmark. Also, 3 of the websites failed to use words, phrases and concepts that users are familiar with. Example: UNAAB's website used words such as Academic Rigor (not known by typical users).
7. Page layout and visual design: 2 university websites have problem with making functionality of buttons that looks clickable, and controls that are obvious from their labels.

8. Search usability: 2 university websites did not have a search box long enough to handle common query lengths; While, some university website search box were too small and looks like only one word will fit in that box.

9. Help, feedback and error tolerance: 7 websites have a problem with loading their pages quickly, like: the EWU website takes more than 5 seconds to load. When giving instructions, pages tell users what to do rather than what to avoid doing for all the websites except for one.

\section{SUMMARY AND CONCLUSION}

The study rationale is aimed at measuring various attributes of the Internet-based platforms to aid deliverable as a user experiences the system, optimize the Internet's diverse search method as well as improve the capacity to deliver information as a user navigates target pages and sites the web, he/she gains knowledge. Thus, web measurement is collection, reporting, updating, analysis and growth of web-based data for the purpose of understanding, improving and optimizing a user's web usage and experience. Web metrics is concerned with the measure of quantifying different attributes of web: websites, web-pages, parts of the website, words in a page, hyperlinks, web search engine results (Kaur and Dani, 2011; Ojugo, 2015) and its visibility to users as they become an indispensable medium for providing a range of information to aid decision making by users in almost all disciplines and facets in life (Ojugo, 2015).

Studies proffer benefits gained via the considering usability of university cum educational websites. Lencastre and Chaves (2008) notes that addressing the challenges in the usability of educational websites will help learners enjoy their learning experience, increase the learner's confidence, and encourage learners to use the site. The results of this research suggest an additional advantage for making educational websites usable. This research proves that considering usability of educational websites can improve the ranking of a university website at one of the major university ranking systems. It is suggested that educational institutions can conduct usability studies in order to improve the usability of their websites and therefore, obtain the advantages of usable educational websites.

Despite the fact that this study is concerned with comparing the results obtained from a university ranking system to the results obtained from the famous usability evaluation method (expert review guidelines), it offers usable results regarding common types of usability problems that can be found on the educational websites and, compared to results obtained from earlier studies. Earlier studies evaluated educational websites usability using the heuristic evaluation method with examples of problems provided that can be found on such websites. 
These problems related specifically to: Outdated content, lack of navigational support links/tools, inconsistency problems (i.e. font size), ineffective internal search functions, language problems (i.e. misspelt words), an inappropriate page design, and incomplete data. These were confirmed by the results and specific examples of problems were identified. This research also provides other types of common usability problems found on educational sites based on qualitative data. The usability problems include: misleading and broken links, orphan pages, image problems, irrelevant information, difficult interaction with a website, and a lack of support to the some languages.

These results obtained, provides insightful and useful data to educational institutions regarding common types of usability problems that could be found on their websites. These issues should be taken into consideration, and should be investigated, and improved in order to improve the overall usability of educational websites, and therefore to obtain the advantages of making educational websites usable.

\section{ACKNOWLEDGMENT}

We acknowledge gratefully Tertiary Education Trust Fund (TetFund) for fully funding this research under the Institution Based Research (IBR) efforts. We, also appreciate our Vice Chancellor Prof. Akii O.A. Ibhadode who has made research a way of life in the Federal University of Petroleum Resources, Effurun. Thank you for the vision. We acknowledge the cooperation and efforts of the all staff of the ICT Unit of Universities mentioned therein and of the Federal University of Petroleum Resources Effurun, for providing server log files and other materials necessary for this research.

\section{REFERENCES}

[1] Agarwal, R and Venkatesh, V., (2002). Assessing a Firm's Web Presence: A Heuristic Evaluation Procedure for the Measurement of Usability, Information Systems Research, 13(2): 168-186.

[2] Astani, M., \& Elhindi, M. (2008). An empirical study of university websites, Issues in Information Systems, 9(2): 460.

[3] Björneborn, L and Ingwersen, P., (2004). Towards basic framework of webometrics, J. of American Society for Information Science and Technology, 55(14): 1216-1227.

[4] Calero, C., Ruiz, J and Piattini, M., (2005). Classifying Web Metrics Using the Web Quality Model, Online Information Review, Emerald Group, 29 (3), 227-248

[5] Dhyani, D., Ng, W., \& Bhowmick, S. (2002). A Survey of Web Metrics, Nanyang Technological University. ACM Computing Surveys, 34(4), 469-503.

[6] Gonzalez, M., Granollers, T and Pascual, A., (2008). Testing Website Usability in Spanish-Speaking Academia through Heuristic Evaluation and Cognitive Walkthrough, Journal of Universal Computer Sciences, 14(9), 15131528.

[7] Gray, W., \& Salzman, C. (1998). Damaged Merchandise? A Review of Experiments that Compare Usability Evaluation Methods. Human-Computer Interaction, 13, 203-261.

[8] Hong, I. (2007). A Survey of Web Site Success Metrics
Used by Internet-dependent Organizations in Korea. Internet Research, Emerald Group, 17(3), 272-290

[9] Kantner, L and Rosenbaum, S., (1997). Usability Studies of WWW sites: Heuristic Evaluation vs Laboratory Testing. ACM 15th International Conference on Systems Documentation, (pp. 153-160). Salt Lake City, UT, USA.

[10] Kaur, A and Dani, D., (2011): The Systematic Review of Web Measurement, International Journal of Computer Science and Engineering Survey, 2(3): 59 - 93, doi: 10.512/ijcses.2011.2305

[11] Kleinberg, J., (1998). Authoritative sources in a hyperlinked environment; In Proc. Ninth Annual ACMSIAM Symposium on Discrete Algorithms, ACM Press, 1998; pp. 668-677.

[12] Kostaras , N., \& Xenos, M. (2006). Assessing Educational Web-site Usability using Heuristic Evaluation Rules. 11th Panhellenic Conference in Informatics, (pp. 197-201). Corfu, Greece.

[13] Lawrence Page, Sergey Brin, Rajeev Motwani, Terry Winogra; The PageRank Citation Ranking: Bringing $\begin{array}{cccc}\text { Order to the Web; } & \text { to }\end{array}$ http://google.stanford.edu/ backrub/pageranksub.ps, retrieved on January 2, 2017.

[14] Leavitt, M.O and Shneiderman, B., (2014). Researchbased web design and usability guidelines,ISBN 0-16076270-7

[15] Lencastre, J and Chaves, J. (2008). Usability Evaluation of Educational Websites, EADTU Conference. France.

[16] Lencastre , J., \& Chaves, J. (2008). A Usability Evaluation of Educational Websites. EADTU Conference. France.

[17] Mayr, P and Tosque, F., (2005). Google web APIs - an instrument for webometric analyses, Proceedings of the ISSI 2005 Conference.

[18] Mukhopadhyay, D., Mishra, P., Saha, D., Kim, Y.C., (2011). A Dynamic Web Page Prediction Model Based on Access Patterns to Offer Better User Latency,

[19] Mustafa, S., \& Al-Zoua'bi, L. (2008). Usability of the Academic Websites of Jordan's Universities. International Arab Conference on Information Technology, (pp. 2-9). Tunisia.

[20] Nielsen, J. (1994). Heuristic Evaluation. New York: John Wiley \& Sons.

[21] Nielsen, J. (2000). Designing Web Usability: The Practice of Simplicity. New Riders Publishing.

[22] Nielsen, J. (2003). Usability 101: Introduction to usability. Retrieved September 15, 2016, from Useit.com: http://www.useit.com/alertbox/20030825.html

[23] Nielsen, J. (2012b). Usability 101: Introduction to Usability. Retrieved from http://www.nngroup.com/articles/usability-101introduction-to-usability/ on January 2, 2017.

[24] Ojugo, A.A., (2015). Accessing web usability and page ranks: a case of some selected universities in Nigerian, Unpublished Technical Report.

[25] Palmer, J. (2002). Web Site Usability, Design, and Performance Metrics. Information Systems Research, 13(2), 151- 167

[26] Papadopoulos, T and Xenox, M. (2008). Quality Evaluation of Educational Websites Using Heuristic and Laboratory Methods, 2nd Panhellenic Scientific Student Conf. on Informatics, Related Technologies, and Applications, Samos, (pp. 43-54). Greece.

[27] Pearson, J., Pearson, A and Green, D. (2007). Determining the Importance of Key Criteria in Web Usability. Management Research News, 30(11), 816-828.

[28] Peterson, K. (2006). Academic web site design and 
academic templates: where does the library fit. Information Technology and Libraries, 25(4), 217-221.

[29] Sandvig, J and Bajwa, D. (2004). Information seeking on university web sites: an exploratory study. Journal of Computer Information Systems, 25(1), 13-22.

[30] Stolz, C., Viermetz, M., Skubacz, M and Neuneier, R. (2005). Guidance Performance Indicator-Web Metrics for Information Driven Web Sites, IEEE/WIC/ACM International Conference on Web Intelligence 2005, 186192

[31] Tarafdar, M and Zhang, J. (2005). Analyzing the Influence of Website Design Parameters on Website Usability. Information Resources Management Journal, 18(4), 62 - 80.

[32] Thelwall, M., (2009), Introduction to webometrics: quantitative web research for social sciences, Morgan \& Claypool.

[33] Toit, M and Bothma, C. (2010). Evaluating the Usability of an Academic Marketing Department's Website from a Marketing Student's Perspective. International Retail and Marketing Review, 5(1), 15-24.

[34] Weiderman and Mgidana, 2004)

[35] Xing and Shen, 2004

[36] Zhang, P and Von Dran, G. (2000). Satisfiers and Dissatisfiers: A Two-Factor Model for Website Design and Evaluation. Journal of the American Society for Information Science, 51(14), 1253-1268.

[37] Zhang, P., Von Dran, G., Blake, P., \& Pipithsuksunt, V. (2000). A Comparison of the Most Important Website Features in Different Domains: An Empirical Study of User Perceptions. Americas Conference on Information Systems (AMCIS'2000), (pp. 1367-1372). Long Beach, CA.

\section{Authors' Profiles}

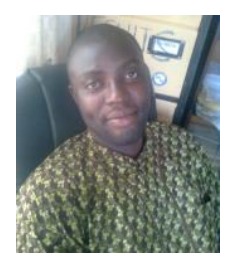

Arnold Adimabua Ojugo received BSc in Computer Science from the Imo State University Owerri in 2000, MSc in Computer Science from the Nnamdi Azikiwe University Awka in 2005, and $\mathrm{PhD}$ in Computer Science from Ebonyi State University Abakiliki in 2013.

$\mathrm{He}$ currently lectures with the Department of Mathematics/Computer Science of the Federal University of Petroleum Resources Effurun, Delta State, Nigeria. His research interests: Intelligent Systems and Control, High Performance and Dynamic Computing, Machine-Learning, Computer Vision, Ubiquitous Computing, Data Security and Forensics. He is an Editor with the Progress for Intelligent Computation and Application, Advancement for Scientific and Engineering Research and SciencePG (ACIS, AJNC, NET and WCMC Journals). He is a member of: The Nigerian Computer Society, Computer Professionals of Nigeria and International Association of Engineers (IAENG).

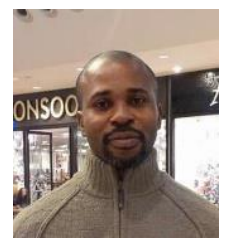

Andrew O. Eboka 'received his HND in Computer Science from Akanu Ibiam Federal Polytechnic in the year 1998, Ebonyi State, PGD from Ebonyi State University in 2013, $\mathrm{BSc} / \mathrm{Ed}$ in Computer Science Education from the Enugu State University of Science and Technology, Enugu in 2013 also and his MSc in Network Computing from Coventry University, United
Kingdom. He currently lectures with the Department of Computer Science Education at Federal College of Education (Technical), Asaba, Delta State, Nigeria.

His research interests include: Network Security and Management, Cyber security, Ubiquitous Computing, Data Security and Forensics. He is a member of: The British Computer Society and Association of Computer Machinery.

How to cite this paper: Arnold A. OJUGO, Andrew O. EBOKA, "Assessing Users Satisfaction and Experience on Academic Websites: A Case of Selected Nigerian Universities Websites", International Journal of Information Technology and Computer Science(IJITCS), Vol.10, No.10, pp.53-61, 2018. DOI: $10.5815 /$ ijitcs.2018.10.07 